\title{
$\Omega$
}

Sarika Raghunath', Manju Bhumenahalli', Apoorv Bhatia²,

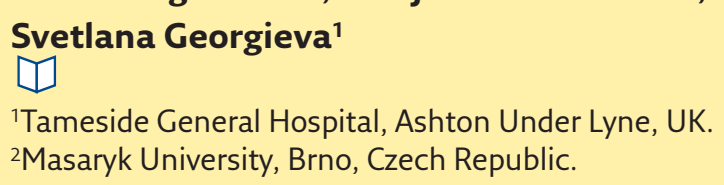

\section{Persistent hypokalaemia and abnormal chest radiography}

\section{Case Report}

A 41 year-old gentleman was referred to the chest clinic with a 10 week history of cough and breathlessness. He was a painter and decorator who was working in the Middle East and had seen the local doctor and had been prescribed two courses of antibiotics and some anti-cough syrup, without any benefit. On returning to UK, he consulted his general practitioner who arranged a chest radiograph and referred him to the chest clinic.

In the clinic consultation, he mentioned that he has been coughing for around 3 months. Over the past 6 weeks he has also become breathless. He had no other significant medical problems. He was working as a painter and decorator on a huge project in the Middle East and had a normal chest radiograph just over 12 months ago. He was a smoker, but did not drink alcohol and never took any illicit drugs.

Examination was normal apart from reduced air entry on the left and dullness to percussion on the left side.
Task 1

What does the chest radiograph (figure 1) show?

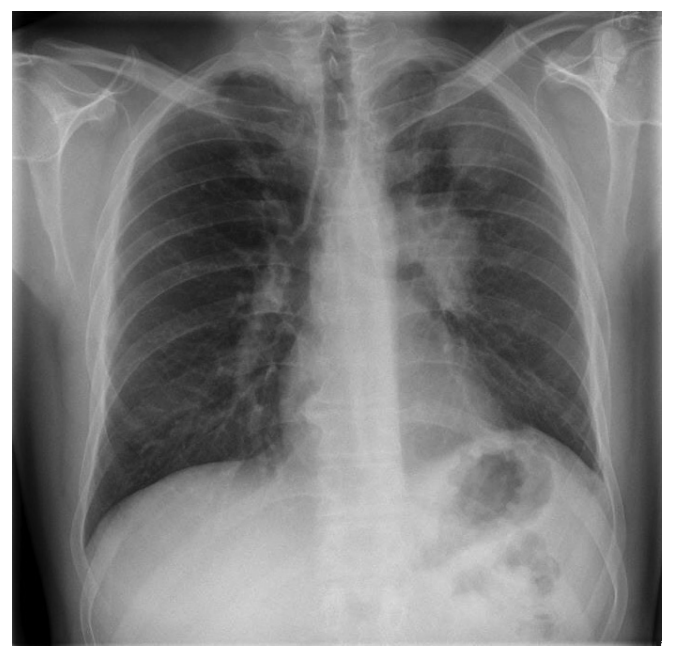

Figure 1 Chest radiograph.
Cite as: Raguhnath $S$, Bhumenahalli M, Bhatia A, et al. Persistent hypokalaemia and abnormal chest radiography. Breathe 2016; 12: 1-5. 


\section{Answer 1}

- Left hilar mass

- Elevated left hemi-diaphragm

- Left upper zone opacity

All the features observed on the chest radiograph are typical of left upper lobe collapse. The left upper lobe collapses anteriorly becoming a thin sheet of tissue under the anterior chest wall, and appears as a hazy or veiling opacity extending out from the hilum and fading out inferiorly.

The radiographic diagnosis was left upper lobe collapse secondary to bronchogenic carcinoma. An urgent staging computed tomography (CT) of the thorax and bronchoscopy was arranged.

\section{Task 2}

What does the CT scan (figure 2) show?

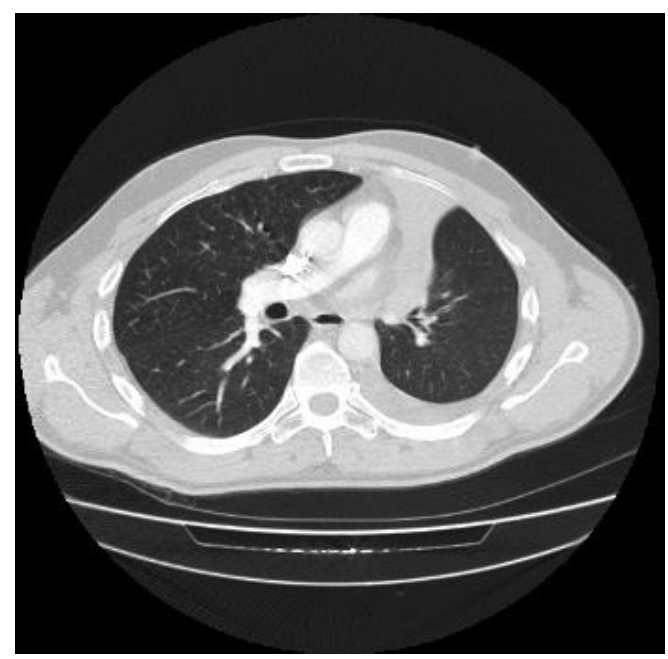

Figure 2 Computed tomography scan. 


\section{Answer 2}

- Collapse of the left upper lobe causing volume loss. The lung tissue is under the anterior chest wall.

- Mediastinal shift to the left.

- Small left pleural effusion.

The bronchoscopy revealed a tumour in the left upper lobe, which histology confirmed to be of small cell origin. As his performance status was 0 , he was referred to the oncologist and treated with chemotherapy in the local cancer hospital.

During the period of chemotherapy he had persistent hypokalaemia ranging from 2.7 to $3.4 \mathrm{mmol} \cdot \mathrm{L}^{-1}$ (normal range: $3.5-5.0 \mathrm{mmol} \cdot \mathrm{L}^{-1}$ ) and was treated with potassium supplements with no effect.

He was readmitted 5 months after the initial diagnosis was made. His partner mentioned that he was very lethargic, had lost weight and was very weak. He was almost bedbound and was clearly deteriorating. A chest radiograph was requested.

\section{Task 3}

What does the chest radiograph (figure 3) show?

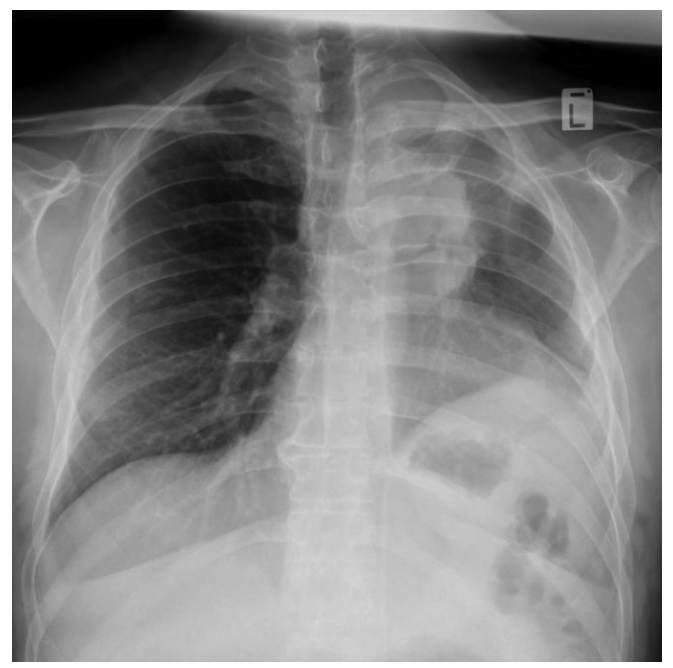

Figure 3 Chest radiograph. 


\section{Answer 3}

Progressive changes with:

- An increase in size of the tumour

- Further lung volume loss (raised left hemidiaphragm)

- Veil-like opacification of the left hemithorax obscuring the left heart border characteristic of left upper lobe collapse

His blood tests were reviewed and his potassium levels are presented in table 1 . The normal range for potassium is $3.5-5.0 \mathrm{mmol} \cdot \mathrm{L}^{-1}$.

\section{Task 4}

Why does he have a persistent hypokalaemia and what test will you order to confirm the underlying cause?

Table 1 Potassium levels of the patient over time

\begin{tabular}{lccccc}
\hline Date & July $\mathbf{9}$ & July $\mathbf{1 3}$ & August 1 & August 2 & August 3 \\
\hline Potassium mmol· $\mathrm{L}^{-1}$ & 3.5 & 3.2 & 2.7 & 2.8 & 2.7
\end{tabular}




\section{Answer 4}

Ectopic adrenocorticotropic hormone (ACTH) production. A test to check ACTH level should be carried out.

The patients ACTH level was inappropriately high at $128 \mathrm{pg} \cdot \mathrm{mL}^{-1}$ (normal levels are up to $48 \mathrm{pg} \cdot \mathrm{mL}^{-1}$ ). He underwent a high-dose dexamethasone test and his morning cortisol level was inappropriately high at $1077 \mathrm{nmol} \cdot \mathrm{L}^{-1}$. This confirmed the ectopic ACTH syndrome due to the underlying small cell carcinoma.

\section{Discussion}

Small cell lung cancer (SCLC) is a neuroendocrine carcinoma that exhibits aggressive behaviour, rapid growth and early spread to distant sites. SCLC is sensitive to chemotherapy and radiation, and frequently associated with distinct paraneoplastic syndromes.

Paraneoplastic syndromes are signs or symptoms that occur as a result of organ or tissue damage at locations remote from the site of the primary tumour or metastases. Paraneoplastic syndromes associated with lung cancer can present as neurological, endocrine, dermatological, rheumatological and ophthalmological syndromes, as well as renal and haematological problems (Trousseau's syndrome). The histological type of lung cancer is generally dependent on the associated syndrome. The two most common paraneoplastic syndromes are hypercalcaemia of malignancy in squamous cell carcinoma and the syndrome of inappropriate antidiuretic hormone secretion in SCLC.

The association between cancer and Cushing's syndrome was first recognised in 1928 in a patient with SCLC [1]. In the 1960s, LIDDLE et al. [2] concluded that ACTH could be produced by non-pituitary tumours. SHEPHERD et al. [3] retrospectively reviewed all the $\mathrm{SCLC}$ in their institution over a 10-year period. Out of 545 patients with SCLC, the incidence of SCLC with ectopic ACTH was $4.5 \%$. They also concluded that SCLC with ectopic ACTH is associated with a low response to chemotherapy, short survival and high rate of complications.

The common causes of ectopic ACTH are small cell lung carcinoma (27\%), bronchial carcinoids (21\%), islet cell tumours of the pancreas (16\%) and thymic carcinoids (10\%) [4].

The diagnosis of SCLC with ectopic ACTH requires awareness of the condition as patients do not present with classical features of Cushing's syndrome such as moon facies. It should be suspected in patients with biochemical features of Cushing's syndrome such as hypokalaemic alkalosis and hyperglycaemia.

In the context of a malignant lesion in the lung, the diagnosis should not be difficult to suspect if the biochemical abnormalities are present and the patient complains of lethargy and proximal myopathy. Typically patients will have high ACTH levels, cortisol levels will fail to be suppressed with high doses of dexamethasone $\left(8 \mathrm{mg} \cdot \mathrm{day}^{-1}\right)$ and there is an absent pituitary adrenal response to corticotrophin releasing hormone.

The treatment is surgical excision of the tumour, but in most cases the tumour may not be resectable due to its metastasis or the patient's poor condition. In these cases medical treatment can be attempted. Medical treatment may have three modes of action [5].

1) "Neuromodulatory" compounds that modulate corticotrophin $(\mathrm{ACTH})$ release from a pituitary tumour. These compounds are bromocriptine, cyproheptadine, somatostatin and valproic acid and are not very effective agents for Cushing's disease.

2) Steroidogenesis inhibitors, such as mitotane, metyrapone, ketoconazole and aminoglutethimide, are the agents of choice for medical therapy of Cushing's disease. These reduce cortisol levels by adrenolytic activity and/or enzymatic inhibition.

3) Glucocorticoid antagonists (mifepristone) block cortisol action at its receptors

Our patient had disease progression and was started on metyrapone. The family was keen to take him home and spend whatever time was left together at home. He died at home a few days later.

\section{Conflict of interest}

None declared.

\section{References}

1. Brown WH. A case of pluriglandular syndrome: "diabetes of bearded women”. Lancet 1928; 212: 1022-1023.

2. Liddle GW, Island DP, Ney RL, et al. Nonpituitary neoplasms and Cushing's syndrome. Ectopic "adrenocorticotropin" produced by nonpituitary neoplasms as a cause of Cushing's syndrome. Arch Intern Med 1963; 111 : 471-475.
3. Shepherd FA, Laskey J, Evans WK, et al. Cushing's syndrome associated with ectopic corticotropin production and smallcell lung cancer. J Clin Oncol 1992; 10: 21-27.

4. Beuschlein F, Hammer GD. Ectopic pro-opiomelanocortin syndrome. Endocrinol Metab Clin North Am 2002; 31: 191-234.

5. Nieman LK. Medical therapy of Cushing's disease. Pituitary 2002; 5: 77-82. 